\title{
Influence of different yeasts on the amino acid pattern of rosé wine
}

\author{
Karin Mandla , Karin Silhavy-Richter, Karin Korntheuer, Martin Prinz, Elsa Patzl-Fischerleitner, and Reinhard Eder \\ Federal College and Research Center of Pomology and Viticulture, Wienerstraße 74, 3400 Klosterneuburg, Austria
}

\begin{abstract}
In an experiment with Rosé wine, 27 different commercial yeasts were tested for their influence on the amino acid pattern of the wine. Amino acids are precursors for aromatic substances; therefore a large variation of the amino acid values in the wine was expected. Blaufränkisch grapes with $20^{\circ} \mathrm{KMW}$ were matured in the cellar with 27 different commercial yeasts. The fermentation was carried out in 341 vessels. The wines were measured for amino acids using an HP 1200 liquid chromatograph and HP-FLD1100 according to Umagat. The wines showed $13.5 \%$ alcohol and little residual sugar. The measurement results of the amino acids of the different wines showed large variations. For example, the amount of the amino acid alanine in wine varied from 17 to $138 \mathrm{mg}$. In particular, the wines of the yeast Pino Type showed the highest amounts of alanine in comparison to the other fermented wines.
\end{abstract}

\section{Introduction}

Amino acids serve as sources of nitrogen for yeasts and as precursors for some aromas [14]. They are building blocks of proteins that are needed for enzymes and the construction of support structures of the cell. For the human body, wine is a good source for undenatured amino acids. Although it is not enough to cover the daily needs, it is a good addition. The various amino acids are incorporated into muscles, tendons, hormones and / or as neurotransmitters [5]. Heated foods [18] make the coverage of daily needs considerably more difficult. Eight amino acids are "essential" for humans; a supply from outside is necessary because they cannot be produced independently. These are: isoleucine, leucine, lysine, methionine, phenylalanine, threonine, tryptophan and valine [5]. Non-essential amino acids, on the other hand, the body is able to produce by itself. But they are not so important. A good source of non-denatured essential amino acids and also good vitamin B suppliers are the yeasts contained in "Sturm" (Austrian partially fermented grape must). Yeasts are generally good nutrient suppliers for humans, since they are rich in vitamins, trace elements and minerals [11]. From the literature it is known that the influence of the yeast results in large differences in the amino acid pattern of the wine $[9,10,16]$. The amino acid contents of the must are mainly influenced by wine-growing techniques [12], but the wine is influenced by various yeasts. The amino acids are often the basis for the formation of aromas and serve as precursors $[1,3,6,7,14]$. Since yeasts have mostly been selected for their ability to develop aromas, it is not surprising that there are great differences in the amino acid pattern of the end wine when using different yeasts, despite the same starting must.

a e-mail: Karin.Mandl@weinobst . at
In particular, the amino acids leucine, valine, isoleucine and phenylalanine are involved in determining the aroma profile [14]. In principle, amino acids are the building blocks of proteins. They consist chemically of a nitrogen and an acid group. They are enzymes or scaffold proteins that are necessary for different metabolic processes of humans and animals [2].

\section{Material and methods}

In this experiment, microvinification was carried out with 27 different commercial yeasts.

Yeast list: Uvaferm WAM, Filtraferm C, Lalvin Opal ICV, Zymaflore Alpha X5, Siha Rubin Cru, Zymaflore X5, Prezisio Red and Fruity, Prezisio Arom C, Fermicru AR2, Littolevure Pink, Siha Active Yeast 3, Oenoferm Freddo, Filtraferm Extract, Filtraferm C Fresh, Lalvin EC 1118, Oenoferm Pino Type, Lalvin Rhone 2056, Siha Active Yeast 8, Actiflore Rosé, Preziso White \& Fruity, Oenoferm Rosé, Fermicru Rosé, Fermiflor, Lalvin Rhone 4600, Oenoferm Rouge, Oenoferm Tipico, Oenoferm Klosterneuburg.

A must of the Blaufränkisch variety was used for this experiment. The grape material came from the vineyard Götzhof in Langenzersdorf. The enzymatic pretreatment as well as the bentonite treatment were carried out in the HBLA cellar in Klosterneuburg. The must had a gradation of $20 \mathrm{KMW}^{\circ}$, a total acidity of $5.1 \mathrm{~g} / 1$ and a $\mathrm{pH}$ of 5.5. The fermentation took place in a double expansion in 34-liter carboys. The fermentation control was carried out using Oenofoss ${ }^{\mathrm{TM}}$ (Foss).

The amino acid spectrum was performed from prefilled wine bottles with a "HP 1200 Liquid" chromatograph and "HP-FLD 1100" according to Umagat [2]. The finished wines showed values of $13.5 \%$ vol. alcohol, very little residual sugar (very strongly dependent on the yeast),

(C) The Authors, published by EDP Sciences. This is an Open Access article distributed under the terms of the Creative Commons Attribution License 4.0 (http://creativecommons.org/licenses/by/4.0/). 


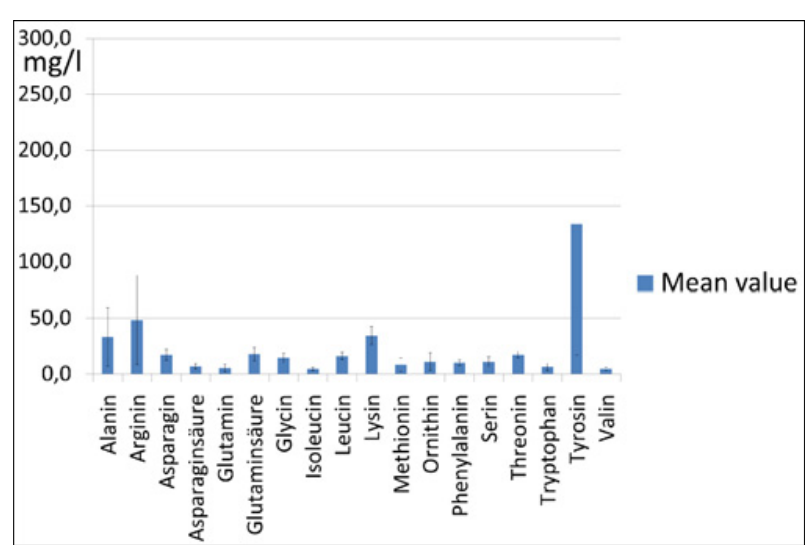

Figure 1. Overview of the investigated amino acids - mean values $(\mathrm{n}=54)$ on all yeasts used (27).

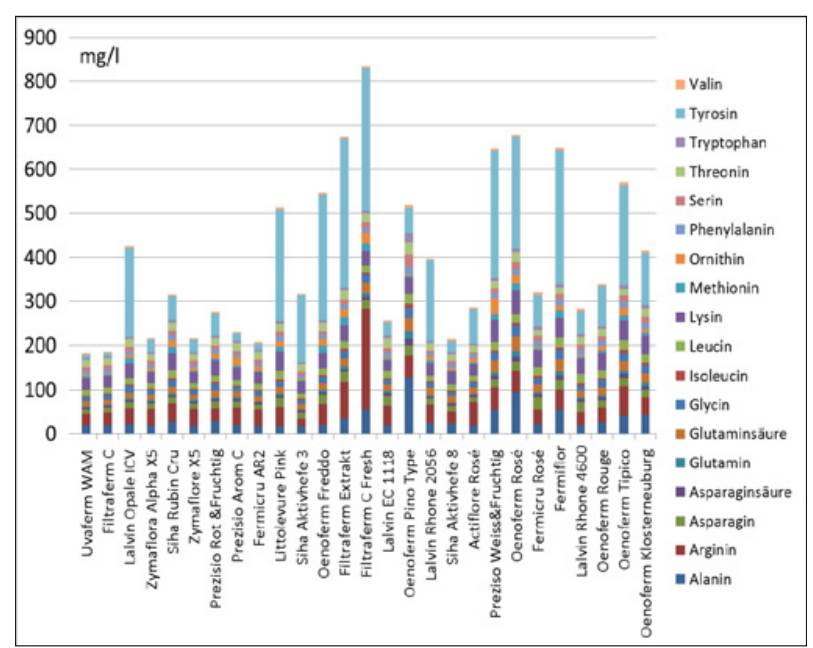

Figure 2. Distribution of the amino acids for the individual commercial yeasts (mean values, $\mathrm{n}=2$ ). The highest amounts reached tyrosine, arginine and alanin.

no glucose, $6.3 \mathrm{~g} / \mathrm{l} \pm 0.3 \mathrm{~g}$ of total acid, a $\mathrm{pH}$ value of 3.4 and volatile acid at $0.4 \mathrm{~g} / 1 \pm 0.1 \mathrm{~g}$.

\section{Results and discussion}

The amino acids examined in the rosé wines are shown in Fig. 1 (overview with standard deviation from the yeast population) and the more precise distribution of the respective amino acids to the corresponding yeasts is shown in Fig. 2.

Alanine can be produced by the yeast itself [2] when ammonia and pyruvic acid are available. It is not an essential amino acid for humans [5]. In this experiment, the various commercial yeasts showed very wide variations between 17 and $138 \mathrm{mg} / \mathrm{l}$ in the wine. The yeasts "Uvaferm WAM", "Filtraferm C", "Zymaflora Alpha", "Prezisio Arom C", "Fermicru AR2", "Littolevure Pink", "Siha Active Yeast 3", "Lalvin EC 1118", "Actiflore Rosé" and "Lalvin Rhone" showed low values. The yeasts "Oenoferm Pino Type" and "Oenoferm Rosé" showed very high contents of the amino acid alanine. In addition, both yeasts had an increased residual sugar value and a detectable lactic acid value.

The measured arginine values varied between 16 and $250 \mathrm{mg} / \mathrm{l}$. The highest levels were found in the yeast
"Filtraferm C Fresh". Arginine is the most important source of nitrogen for yeasts in wine. This is a semiessential amino acid [5], which means that it must be absorbed in some situations with the food and serves as a dietary supplement for certain ailments.

Asparagine is a good source of nitrogen for yeasts [17] and has a negative influence on the formation of succinic acid. It is a non-essential amino acid for humans [5]. The consumption of the yeasts varies. The values ranged from 9 to $27 \mathrm{mg} / \mathrm{l}$. The lowest value was found in the yeast "Uvaferm WAM" and the highest in "Fermicru Rosé".

Aspartic acid is a good source of nitrogen for yeasts [17] and is not an essential amino acid for humans. Values of 4.5 to $14 \mathrm{mg} / \mathrm{l}$ were measured. The highest values were found in "Oenoferm Pino Type".

Glutamine is an important amino acid for plants and animals. It is incorporated in high concentrations in the muscle and shows an anabolic effect. Basically, this amino acid can be formed by the human body itself [5]. The highest values were measured with "Oenoferm Pino Type". The values ranged from 2.3 to $18.1 \mathrm{mg} / \mathrm{l}$.

Glutamic acid is the basis for succinic acid formation [2]. In the presence of asparagine, the formation of succinic acid decreases. The glutamate in food is the ester and salt of glutamic acid. The umami taste is a full flavor, which is why glutamate is often used as a food additive. The amino acid can be formed by the body itself. The highest values in the wine were found in "Oenoferm Pino Type". The values ranged from 10.1 to $34.4 \mathrm{mg} / \mathrm{l}$.

Glycine is characterized by its sweet taste. It is contained in all proteins and tissues in the human body and can be produced by itself. The values were 8.4 to $28.3 \mathrm{mg} / \mathrm{L}$ and the highest value was found with "Oenoferm Rosé".

Isoleucine is an essential amino acid for the human body. It serves as an endogenous source of energy in hunger phases and regulates some hormones in the body, such as the stimulation of the insulin release and the release of the growth hormone somatotropin [5]. A deficiency of isoleucine leads to muscle weakness and lack of drive.

In wine, isoleucine is a precursor for the fruity fatty acid (2-methylbutyric acid) and the pineapple tone (ethyl 2-methylbutanoate) [14]. The decomposition and conversion is carried out according to the Ehrlich metabolic pathway [4]. The values ranged from 2.8 to $9.8 \mathrm{mg} / \mathrm{l}$. The highest values were produced by "Oenoferm Pino Type".

The amino acid leucine is an essential amino acid and plays a central role in the energy balance of the muscle cell. It is the basis for muscle building and is involved in the healing of wounds [5]. In wine, leucine precursors [14] are fruity, nutty notes (isovaleraldehyde), rancid, rotted fruit and cheese tones (isovaleric acid), apple tones (ethyl isovalerate), fruity banana and pear tones (acetic acid isopentyl esters) and formation of fusel alcohol (isoamyl alcohol). The measured values were 11.6 and $24 \mathrm{mg} / \mathrm{ml}$. The highest value was produced by "Oenoferm Pino Type".

Yeast is a good source for lysine [5]. It is an essential amino acid. It is responsible for the development of collagen. The values in the wine were 22.3 to $54 \mathrm{mg} / \mathrm{l}$, with the highest value for "Preziso White \& Fruity".

Methionine is a sulfur-containing essential amino acid. It is involved in the formation of glutathione [5] and provides methyl groups for various chemical processes. 
The highest value was found in "Siha Rubin Cru"; the other values were between 2 and $22 \mathrm{mg} / \mathrm{l}$.

Ornithine is not an essential amino acid. The highest value was found in "Preziso White \& Fruity", the other values were between 2.5 and $38.8 \mathrm{mg} / \mathrm{l}$. In the human body it shows effects on somatotropin and insulin (endogenous hormones) [5].

Phenylalanine is synthesized in plants via the shikimic acid pathway [2]. The flavonoids from phenylalanine can be biosynthesized via the pathway of cinnamic acid. By 4-hydroxylation from phenylalanine L-tyrosine in the human body is formed, L-tyrosine is involved in the synthesis of hormones such as adrenaline, noradrenaline and melanin. In wine, phenylalanine is a precursor for rose, honey and flower tones (2-phenylacetate) [14]. The values in the wine ranged from 7.1 to $18 \mathrm{mg} / \mathrm{l}$.

Serine is a non-essential amino acid and can be prepared from threonine, glycine or glucose. Serine forms the basic structure of many membranes and is involved in the formation of the amino acids cysteine and tryptophan [5]. In addition, serine is involved in the formation of the neurotransmitter acetylcholine - a substance that plays an important role in the neuronal transmission of nerve impulses [13]. The values in the wine were between 5.9 and $31.5 \mathrm{mg} / \mathrm{l}$.

Threonine is an essential amino acid for the human body. The highest value was produced by "Oenoferm Pino Type". The other wines varied from 12.7 to $29.6 \mathrm{mg} / \mathrm{l}$.

Tryptophan is an essential amino acid and represents the precursor for the happiness hormone serotonin [5]. It is produced by plants and microorganisms and the estimated daily requirement is 3.5 to $6 \mathrm{mg} / \mathrm{kg}$ body weight. The values in the wines were from 4 to $23.3 \mathrm{mg} / \mathrm{l}$.

Tyrosine is not an essential amino acid and is produced from phenylalanine. It is the starting substance for the biosynthesis of DOPA (L-3,4-dihydroxyphenylalanine), dopamine, catecholamines, melanin, thyroxine and tyramine (neurotransmitters and thyroid hormones) and a component of all proteins [5]. In the wines, the values were 6.7 to $352 \mathrm{mg} / \mathrm{l}$.

Valine is a precursor in wine for apple flavor (isobutyraldehyde, isobutyric acid), fruity notes (isobutanol) and the banana tone (isobutyl acetate) (Styger et al., 2011). Grapes harvested later have a higher valine content. For the human body, valine is an essential amino acid and an essential building block for proteins and muscle building. The contents in the wines varied between 1.1 and $6.8 \mathrm{mg} / \mathrm{l}$.

Proline is not an essential amino acid and is not metabolized by yeasts [8]. The values were shown for different yeasts from $920 \mathrm{mg}$ to $1,460 \mathrm{mg} / \mathrm{l}$. The amino acid proline can be produced by the human body from glutamate. In the presence of vitamin $\mathrm{C}$, proline is incorporated into collagen as L-hydroxyproline and determines its mechanical properties. Deficiency results in scurvy [5].

It was demonstrated that yeasts have a certain requirement of amino acids. Above all, the essential amino acids are needed as precursors for building aromas. The question is how much can be actively influenced by viticulture treatments and the choice of yeast.

\section{References}

[1] T. Bauza, A. Blake, F. Daumas, J.C. Cabanis, Journal of Chromatography A. 707, 373-379 (1995)

[2] J.B. Berg, J.L. Tymoczko., L Stryer, Biochemie 5.Auflage, Spektrum Akademischer Verlag, Heidelberg, Berlin (2003)

[3] R.M Callejón., A.M. Troncoso, M.L. Morales, Talanta 81, 1143-1152 (2010)

[4] F. Ehrlich, Ber Dtsch Chem Ges 40, 1027-1047 (1907)

[5] U. Gröber, Mikronährstoffe, 3.Auflage, Wissenschaftliche Buchgesellschaft (2010)

[6] P. Hernández-Orte, M.J. Ibarz., J. Cacho., V. Ferreira, Food Chemistry 98, 300-310 (2006)

[7] M.G. Lambrecht, I.S. Pretorius, S.Afric. J. Enol. Vitic. 21, 200 (2000)

[8] P. Lehtonen, Am.J.Vitic. 47, 2 (1996)

[9] A. J. Martínez-Rodríguez, A. V. Carrascosa, P. J. Martín-Álvarez, V. Moreno-Arribas, M. C. Polo., Journal of Industrial Microbiology and Biotechnology 29, 6, 314-322 (2002)

[10] V. Moreno-Arribas, E M. Pueyo, C. Polo, P. J Martín-Álvarez J., Agric. Food Chem. 46, 4042-4051 (1998)

[11] J Schormüller. Alkoholische Genussmittel (Springer Verlag, Berlin Heidelberg, 1968)

[12] A. Schwab, M. Peternel und E. Grebner, Rebe und Wein, 10, 25-30 (2003)

[13] S. Silbernagl, Taschenatlas Physiologie, (Georg Thieme Verlag, Stuttgart, 2012)

[14] G. Styger., B. Prior, F.F. Bauer, J. Ind. Microbiol. Biotechnol 38, 1145-1159 (2011)

[15] H. Umagat, P. Kucera, L.F: Wen, J. Chromatogr. 239, 463-474 (1982)

[16] E. Valero, C. Millán, J.M. Ortega, J. C. Mauricio: Journal of the Science of Food and Agriculture 83, 830-835 (2003)

[17] G. Würdig, R. Woller, Chemie des Weines (Ulmer Verlag, Stuttgart, 1989)

[18] T.Y. Yu, J. D. Morton, S .Clerens, J. M Dyer, Food Science and Food Safety 16, 141-159 (2017) 